\title{
VIAJEROS ESPAÑOLES POR EUROPA EN LOS AÑOS CUARENTA DEL SIGLO XIX: TRES FORMAS DE ENTENDER EL RELATO DE VIAJE
}

\author{
Julio PeÑAte Rivero \\ Université de Fribourg-Suisse
}

\section{RESUMEN}

En la historia de la literatura de viajes española, la década de los años cuarenta del siglo XIX ocupa un lugar particular: después de las guerras napoleónicas y de la primera guerra carlista, se produce una relativa calma que no sólo favorece los viajes de los extranjeros hacia España, sino también los de los españoles hacia el exterior de la península ibérica. Entre las posibilidades más atractivas se encuentran Francia, Bélgica, los Países Bajos y Alemania. La diversidad de los textos disponibles permite distinguir al menos tres variantes o perspectivas: el relato como descubrimiento, como verificación y como manual de viaje. Este artículo se propone reflexionar sobre estas diversas perspectivas a partir de autores representativos, cuyos itinerarios son en parte semejantes: Modesto Lafuente, Ramón Mesonero Romanos y Ángel Fernández de los Ríos. Insistiremos en el primer autor por su especial contribución a la historia de la literatura viática y, una vez presentada la obra de los demás, terminaremos con unas breves conclusiones para comparar las variantes estudiadas.

Palabras clave: literatura de viajes en el siglo XIX, el viaje en el Romanticismo, relato de viajes y guía de viaje, historia y crítica, Modesto Lafuente, Mesonero Romanos, Fernández de los Ríos.

\section{SPANISH TRAVELERS ROUND EUROPE IN THE 1840's: THREE WAYS OF UNDERSTANDING THE TRAVEL LITERATURE}

\begin{abstract}
In the history of the Spanish travel literature, the 1840s have a particular place: after the Napoleonic Wars and the first Carlist War came a period of relative calm which encouraged visitors to Spain but also the Spanish to travel outside the Iberian Peninsula. France, Belgium, Netherlands and Germany are among the most attractive options. The variety of available texts gives the possibility to distinguish between at least three variants or perspectives: the travel story as discovery, as verification and as travel guide. This article intends to introduce these diverse perspectives from representative authors whose itineraries are partly similar: Modesto Lafuente, Ramón Mesonero Romanos y Ángel Fernández de los Ríos. There will be a special emphasis on the first author because he contributed in a special way to the history of the travel literature. Once the work of the others has been presented, there will be a brief conclusion to compare the variants presented.
\end{abstract}


Key Words: Travel Literature in the $19^{\text {th }}$ century, travel in Romanticism, travel writing and travel guide, history and criticism, Modesto Lafuente, Mesonero Romanos, Fernández de los Ríos.

Una vez superada la «ominosa década» fernandina con su cortejo de represión y de expatriaciones forzadas y terminada la primera guerra carlista en 1840, España entra en un periodo de relativa tranquilidad (que no de estabilidad) respecto a los años anteriores. Ello se percibe en numerosas manifestaciones sociales como las que permiten el cultivo de diversas artes y, entre ellas, la de viajar por el placer de hacerlo, dentro de la península y por el exterior. Desde principios de los años cuarenta se puede observar un crecimiento notable de esta actividad, tanto por parte española como extranjera (en este caso hacia España, convertida en atracción al mismo tiempo cercana y exótica para el visitante europeo ${ }^{1}$ ). Como fino observador de las costumbres hispanas desde dentro y fuera de España, Eugenio de Ochoa comenta la situación con la perspectiva que le otorgan sus prolongadas estancias en París (1829-1834 y 1837-1844):

Esto de viajar por recreo puede considerarse como usanza esencialmente moderna, a lo menos en España, si hemos de creer lo que nos cuentan nuestros padres y más aún nuestros abuelos. Todavía a principios de este siglo, un hombre que había pasado la raya de Francia y penetrado hasta las murallas de Bayona, era ya una especie de fenómeno; se le llamaba cosmopolita; al que había llegado a Burdeos, se la consideraba como un intrépido viajero, un capitán Cook; llegar a París era cosa excesivamente inverosímil, temeridad en que rarísima vez se creía [...] ¿Qué diferencia entre esto y lo que sucede en el día! Así es que ahora, por el contrario de lo que pasaba hace un siglo, lo extraño, lo increíble es, en ciertas clases de la sociedad, un hombre que no ha salido de España ${ }^{2}$.

Al margen de la exageración, habitual en la ironía de Ochoa, esta cita permite apreciar el cambio de situación operado en la primera mitad del siglo XIX en cuanto a la práctica libre del viaje se refiere. Tanto es así que, en torno a 1840, «el español fuera de España» puede considerarse como un tipo de personaje lo bastante común para figurar en la serie de Los españoles pintados por sí mismos, tipo que no ha de confundirse con el del emigrante, al que Ochoa dedica otro artículo en la misma publicación.

\footnotetext{
${ }^{1}$ Esa afluencia, sobre todo francesa, a España, acaba diluyendo el exotismo y provoca comentarios como el siguiente de Achard (que recuerda el del embajador español ante Luis XIV): «Entre la Puerta del Sol et le quai Voltaire, il n'y a vraiment plus de Pyrénées». Amédée Achard. Un mois en Espagne (octobre de 1846). París, Ernest Bourdin, 1847, p. 60.

${ }^{2}$ OCHOA, Eugenio de. «El Español fuera de España». En: VV.AA. Los españoles pintados por sí mismos. Madrid: I. Boix Editor, 1844, t. II, pp. 442-451.
} 


\section{El DesCubrimiento DE EuRopa EN Modesto LAFuente}

No obstante, como veremos enseguida, la experiencia viática no suele conducir a la de la escritura entre los viajeros cultivados y capacitados para la producción literaria. Y es en este contexto donde interviene Modesto Lafuente con Viajes de Fray Gerundio, relato en dos tomos del periplo realizado en 1841. El primero se dedica a la salida de Madrid hacia Burgos, Vascongadas, Bayona, Burdeos, Angulema y París. El segundo recoge el resto de su trayecto: Bélgica (Bruselas, Lieja, Gante, Brujas, Amberes) Holanda (Breda, Rotterdam, La Haya, Leiden, Amsterdam, Utrecht), Alemania (Düsseldorf, Colonia, Aquisgrán) y el regreso por Francia.

Lo primero que destaca en la obra del autor palentino son las reflexiones del narrador respecto a su propio relato, recogidas en la presentación del texto. Dicha presentación reviste un interés especial en la literatura viática, ya que suele ser redactada cuando el autor posee una visión global de su doble obra, el viaje y la composición del texto, y funciona como marco de este último, completado a veces por comentarios que cierran el relato a modo de balance o de resumen sobre el viaje o sobre el libro que lo relata. Por ello importa notar la vacilación del presentador para situar el texto dentro de las letras hispanas: «relación o reseña o apuntes o memorias u observaciones o recuerdos, que no sé de verdad qué nombre merezcan y tú [lector] les darás el que en tu discreción y buen juicio te parezca más acomodado» ${ }^{3}$. La vacilación terminológica no es casual sino que alude a la situación de una forma discursiva que el autor considera todavía escasamente desarrollada en nuestras letras y por ello, como nos dirá más tarde, quisiera «estimular a otros ingenios más felices a que con mejor cortadas plumas cultiven un género de escrito que no abunda ciertamente en España» ${ }^{4}$. Hay, pues, conciencia de estar cultivando una serie literaria particular, con características propias, aunque poco desarrollada en el país, y hay también propósito, formulado en términos de falsa modestia, de contribuir a su crecimiento a través de la propia obra.

Por otra parte, y siempre sin salir del prólogo inicial, se afirma la ausencia de toda ambición que no sea la de informar con llaneza sobre lo visto: el único objetivo será exponer las cosas como ellas se manifestaron ante el

${ }^{3}$ LAFUENTE, Modesto. Viajes de Fray Gerundio por Francia, Bélgica, Holanda y orillas del Rhin. París: Librería de Garnier Hermanos, 1861, p. V. En la continuación citaremos por esta edición, actualizando la grafía cuando el caso lo requiera. La primera, de 1842, se publicó en Madrid: Establecimiento Tipográfico, Calle del Sordo, n. ${ }^{\circ} 11$.

${ }^{4}$ LAFUENTE, ibidem, p. 264. Justo antes de esta cita, Fray Gerundio afirma: «Pero ya he pagado a mi patria el tributo que como viajero le debía»; dicho en otros términos, parece considerar como deber cívico el hacer que sus conciudadanos se beneficien de la experiencia que él ha vivido. 
propio viajero. Ahora bien, la petición previa de disculpas por un estilo descuidado y la pretensión de veracidad es un recurso habitual de la narrativa viática, que a veces utiliza el primero como garantía de la segunda: la «no atención» a la composición vendría a mostrar que lo importante para el narrador es la verdad de lo que nos cuenta. El desaliño, real o pretendido, se convierte en vehículo de transparencia al supeditar la preocupación formal a la autenticidad pretendida de lo relatado. Y ello sería válido en un texto como el actual, que utiliza una fórmula narrativa particularmente eficaz, según hemos de ver. Así pues, las disculpas por el escaso mérito literario de un texto determinado pueden sugerir que este género narrativo tiene sus exigencias estéticas y que el autor reconoce no haber llegado a cumplirlas, pero prevenir al lector de esas limitaciones también puede considerarse como un recurso retórico destinado a que baje el listón de sus expectativas y quede así gratamente sorprendido con los eventuales logros estéticos del texto. En nuestra opinión, esto es lo que va a suceder en Viajes de Fray Gerundio: la advertencia de desaliño forma parte de su estrategia expositiva.

En efecto, puesto en relación con las características habituales de la narración viática factual (la correspondiente a un desplazamiento físico efectivamente realizado), este relato cumple con una gran cantidad de ellas, incluso de las más exigentes: estamos ante la narración de un solo viaje y no ante la refundición de varios como a veces se encuentra en la literatura viática 5 . Además, no se trata de un desplazamiento forzado (por exilio, emigración, enfermedad u otros motivos) sino voluntario, «de pura instrucción y recreo» (p. 526), según afirma Fray Gerundio, lo cual no impide que haya motivos más concretos como un proyecto de escritura (convertir en texto la experiencia del viaje), razones económicas o profesionales, etc. Al igual que todo gran viaje, este se realiza de lo conocido a lo desconocido aunque sea en el ámbito europeo, lo que implica el descubrimiento de marcos naturales, urbanos y sociales nuevos y distintos entre ellos. Esta narración abarca el conjunto del periplo, la ida y la vuelta, frente a las que dejan fuera o apenas aluden al regreso ya que todo lo interesante sucedió a la ida, el retorno repite el itinerario o se ha optado por un camino más rápido, etc. El viaje es la condición y centro del relato, no una ocasión o pretexto para explayar la subjetividad del autor: sus gustos, pasiones, recuerdos, saberes o ideología.

Tampoco se trata de alinear descripciones de lugares, narraciones históricas o leyendas sino de privilegiar la visión del objeto y la reacción del viajero frente a él, lo cual sí puede derivar hacia la descripción o la in-

\footnotetext{
${ }^{5}$ Precisemos que cualquiera de las características citadas a continuación puede encontrarse en otras series literarias: lo importante para la nuestra es la cantidad y la intensidad de su presencia; la reunión de ambas es lo que imprime carácter propio a la literatura viática.
} 
formación histórica, por ejemplo. Lo anterior implica que no estamos ante una guía turística, con su acumulación de datos pretendidamente válidos y suficientes para quien prefiera ser guiado más que ser protagonista de su periplo: el relato de viaje puede apoyarse en la guía pero no se confunde con ella. El texto incluye también elementos de lo que podríamos calificar como balance final, al concluir el trayecto: el viajero siente dejar los países visitados, de los que aprecia su prosperidad, seguridad y paz (algo envidiable para una España casi recién salida de una guerra civil), pero rechaza su materialismo, el egoísmo de sus habitantes y su exagerado afán de lucro (p. 526). Otro ingrediente que suele servir de referencia para estimar la relevancia del viaje es el impacto, huella o transformación que deja en su protagonista; un breve periplo de cuatro meses y medio no modifica forzosamente la propia visión del mundo (el viajante asegura volver tan español como salió), pero en algo ha influido cuando se afirma que al regresar a España «la encontramos unos cuantos grados más descuadernada y más desvencijada que cuando la habíamos dejado» (p. 531, palabras que cierran el relato).

Podríamos detenernos igualmente en los componentes metanarrativos, que no suelen faltar en la literatura de viajes, como lo muestra el siguiente ejemplo, en el que el viajero reflexiona sobre su propia narración: «El tomo crece y el viaje no se acaba, y por más que me he propuesto ser compendioso y sucinto, por más que he procurado entresacar del abundoso campo de mis apuntes de viaje puramente lo que me ha parecido necesario [...] ya es forzoso recoger velas y tocar a nueva retirada desde Colonia» (p. 498; nótese la alusión a las varias etapas de realización del texto: experiencia viática, apuntes escritos, selección y reelaboración final). Pero nos interesa sobre todo el tratamiento reservado aquí a la habitual identidad viática entre narrador, protagonista y autor: si bien se respeta la unidad de narrador y protagonista (la historia realizada y contada por el mismo personaje), parece que el autor no corresponde al viajero, dado que este se presenta como Fray Gerundio, clérigo exclaustrado al que acompaña su fiel servidor, el lego Pelegrín Tirabeque: apuntemos, en primer lugar, que Fray Gerundio aparece como personaje, en compañía de su criado, en buena parte de la producción de Lafuente ${ }^{6}$, por lo que supera la simple categoría de seudónimo del autor. Casi diríamos que es Tirabeque quien impide considerarlo como tal, ya que este es claramente un personaje creado, que interactúa (viaja, sirve, comenta, pregunta, discute) con su amo y de este modo lo «absorbe» consigo hacia el mundo de la ficción. Podemos

\footnotetext{
${ }^{6}$ Además de la obra que aquí tratamos interviene al menos en Fray Gerundio. Periódico Satírico de Política y Costumbres (1837-1844), Fray Gerundio. Revista Europea (18481849), Viaje aerostático de Fray Gerundio y Tirabeque (1847) y en Teatro social del siglo XIX (1846: artículos de crítica social).
} 
considerar que Lafuente opera aquí un doble proceso: por una parte, de proyección, sobre todo en Fray Gerundio (que corresponde a la cultura, talante, curiosidad, sentido crítico, etc. del autor) y, por otra, de distanciación, dado que el personaje permite que Lafuente descargue en él la responsabilidad de sus propósitos, basándose precisamente en la diferente identidad de ambos. Se opera así el recurso a la ficcionalización, precisamente para poder expresarse con más contundencia y fidelidad respecto a lo que se desea comunicar: como en tantas otras ocasiones, la mentira de la ficción viene a ser el mejor vehículo de la propia verdad ${ }^{7}$.

No hay, pues, identidad total entre autor y personaje, como de hecho sucede en el relato de viaje, en las memorias o en la autobiografía. Lo que hace Lafuente es explicitar la presencia de ese recurso, como para liberar su responsabilidad y censurar con mayor facilidad e ironía cuando la ocasión se presente. Además, el recurso permite conseguir una notable variedad expositiva ${ }^{8}$ basada en dos estrategias; por un lado, se presenta lo visto mediante una cierta dramatización: dos personajes que interactúan ante el lector a través del diálogo, como para compensar las extensas secuencias informativas a cargo de Fray Gerundio. La información nos llega así repartida entre amo y criado, cada uno con su manera propia de reaccionar ante lo que ve: la culta y mesurada de Fray Gerundio, la espontánea, elemental e ingenua de Tirabeque ${ }^{9}$. Por otro lado, se juega hábilmente con la intertextualidad acudiendo a la pareja de interlocutores más ilustres de la narración española: Fray Gerundio no deja de recordar a don Quijote en su calidad de amo, leído, sensato en sus reflexiones, dialogante y opuesto al sanchopancesco Tirabeque ${ }^{10}$, materialista, de reacciones epidérmicas, miedoso y básicamente interesado por lo inmediato ${ }^{11}$.

\footnotetext{
${ }^{7}$ Pensemos, a contrario, en el relato autobiográfico, cuya factualidad ha sido cuestionada, entre otros autores, por Philippe Lejeune en sus diversas publicaciones sobre el tema, especialmente a partir de Le Pacte autobiographique (1975) y de Je est un autre (1980).

${ }^{8}$ Esa variedad, que es también objetivo del relato viático, Fray Gerundio la ha intentado y piensa haberla conseguido, según afirma modestamente al inicio del segundo volumen: «Si buscas variedad, hermano lector, no dejarás de hallarla, pero tampoco te faltará en qué ejercitar la virtud de la indulgencia» (p. 264).

${ }^{9}$ Así se percibe en casi todas las novedades que descubren: ver, por ejemplo, el diálogo a propósito del palacio de las Tullerías, en París (pp. 149-153) o el pánico del criado al oír la palabra dieta (p. 494) y vincularla con la alimentación, por ignorar que se trata de la asamblea de los dignatarios alemanes. Los malentendidos, terminológicos o de otro tipo, abundan en el texto para insistir en la ignorancia de Tirabeque y explicar al lector de qué se trata en cada caso.

${ }^{10}$ Sus nombres ya son reveladores: si el de Fray Gerundio remite a una referencia culta y célebre, la novela satírica del Padre Isla, el de Tirabeque lo hace a otra popular y alimenticia (guisante blando o vaina tierna y casi plana cuyos guisantes se distinguen desde fuera).

${ }^{11}$ Anotemos que se puede hablar incluso de otro personaje, colectivo en este caso: el lector, al cual se dirige el narrador con cierta frecuencia, como para que se sienta próximo al viajero, comprenda sus peripecias o le siga en la lectura: «figúrese el lector» (p. 412), «el hermano lector» (p. 480), «lectores míos» (p. 518), etc.
} 
Para terminar este breve repaso sobre los elementos compositivos de la obra, citaremos la presencia de un tipo de personaje esencial en el relato viático, que puede manifestarse tanto de manera individual como colectiva: nos referimos al Otro, al conjunto de individuos o de grupos humanos pertenecientes a culturas y formas de vida distintas de la propia, con quienes el viajero toma contacto a lo largo de su periplo: la relación, estrecha o no, con la alteridad es una garantía de haber viajado y de no sólo haber cambiado de lugar, por lo que constituye una condición habitual del relato viático. Pues bien, en esta obra se aprecia una constante curiosidad por el Otro de los países visitados: hábitos alimenticios, organización económica, prácticas culturales, legislación, especificidades lingüísticas ${ }^{12}$, etc., en consonancia con el objetivo viático ya citado anteriormente: un viaje «de pura instrucción y recreo».

Si nos centramos ahora en la materia del texto, hemos de empezar señalando el propósito inicial de los viajeros: describir con imparcialidad lo que ven en su recorrido, algo que parece evidente pero que no lo es si se observa el tratamiento dado a España por los visitantes extranjeros. Fray Gerundio toma como ejemplo a evitar Guide du voyageur en Espagne et en Portugal ${ }^{13}$, de Quétin, texto plagado de tópicos, imprecisiones y datos totalmente anticuados: España es un país de alcaldes armados con espada, de pasión incontenible por la danza, del bolero como baile de alta sociedad, de sesenta mil misas al día y veintiún millones al año: «Así pues, no es extraño que los extranjeros tengan tan equivocadas ideas de nuestro país» (p. 54) $)^{14}$.

${ }^{12}$ En este terreno citaremos un ejemplo que muestra la receptividad del viajero: Fray Gerundio no duda en incorporar a nuestra lengua el siguiente neologismo: «Flaneaba yo por el boulevard de los Italianos». El vocablo, derivado del francés flâner, corresponde a un comportamiento frecuente en el turista, que el viajero define en nota a pie de página como pasear curioseando por calle sin más objetivo que... curiosear (p. 132). La no existencia de un término propio en castellano puede ser reveladora de la diferencia de comportamientos y de desarrollo turístico entre Francia y España. En su momento veremos que Mesonero Romanos menciona el mismo problema y sugiere una traducción parecida.

${ }^{13}$ Se trata de la edición de 1841(muy poco anterior a la aparición de Viajes), publicada en París por Librairie de Maison, Editeur des Guides Richard. Venía precedida de un vocabulario y de un manual de conversión francés-español, ambos bastante reveladores de las presumibles necesidades comunicativas de los visitantes franceses.

${ }^{14}$ Fray Gerundio no sólo fustiga a los extranjeros: también critica a los españoles por no haber escrito obras que ofrezcan una imagen real y actual del país. Por culpa de unos y otros, el viajero hispano ha de aclarar si las señoras llevan el puñal en la liga, si los toros se corren en los teatros o si los novios se pasan el tiempo tocando la guitarra bajo la ventana de su amada (p. 55). Mientras Fray Gerundio se ríe de tanta ignorancia, Tirabeque se indigna de que a pesar de ello un forastero se atreva a escribir sobre España (p. 166). El editor Mellado publicará un Apéndice a la obra francesa, movido por sus falsedades y para contrarrestar su éxito entre los extranjeros, pero reconoce las dificultades de hacerlo «sin estadísticas, sin buenos diccionarios geográficos, sin manuales de las poblaciones importantes, 
El segundo punto destacable es el «catálogo» que ofrece Viajes de Fray Gerundio de casi todo aquello que debe retener la atención del visitante, una lista en buena medida válida para la literatura viática posterior: transporte, alojamiento, lengua, edificios religiosos y civiles de interés artístico y otros monumentos, museos, bibliotecas, librerías, plazas, bulevares y paseos, casas y cementerios de personas ilustres, así como todo lo que revista valor histórico, lugares representativos de la economía del lugar (fábrica de máquinas de trenes en Lieja, de cerveza en Lovaina, etc.), comportamientos curiosos de los nativos, como la forma de alimentarse o la puntualidad en las citas y en los horarios en general, datos históricos del lugar, tradiciones y costumbres (en Rotterdam la de «vestir» el aldabón de las puertas con motivo de un nacimiento), etc., sin olvidar todo lo que no sólo justifique el interés del viajero sino también su presencia en el texto viático.

El tercer punto son los fundamentos o criterios de tal interés: si el periplo ha sido de instrucción y recreo para los viajeros, el libro ha de serlo para el lector. Y esta atención hacia el receptor se percibe en la combinación de informaciones históricas y artísticas con observaciones y comentarios, serios o jocosos, sobre la vida en las ciudades y países visitados. Dichas observaciones raramente son gratuitas: se las suele presentar de manera favorable o desfavorable, como pensando en su utilidad o peligro para la sociedad española. Así pues, el afán aleccionador subyace, cuando no está claramente explicitado, bajo la elección de lo que se presenta al lector, ya sea en clave de elogio o de censura abierta o moderadamente irónica. Fray Gerundio se muestra impresionado por temas tan diversos como la riqueza de vida teatral en París (veinte teatros abiertos cada día en la «ciudad mundo»), las cárceles educativas para jóvenes en Francia, los guías turísticos organizados e identificados con placas en Alemania, el afán de los holandeses por inmortalizar a sus artistas, el funcionamiento de los trenes en Bélgica, etc. En cambio, critica el egoísmo, el individualismo y el afán

sin armonía en la distribución territorial, sin datos históricos, sin nada en fin de cuanto es importante para hacer una buena guía del viajero». MELLADO, Francisco de Paula. Apéndice a la Guía del viajero en España. Madrid: Establecimiento Tipográfico, calle del Sordo, n. ${ }^{\circ} 11,1842$, p. V). Añadamos también que, en otra de sus obras, Lafuente apunta el peligro de que los españoles puedan llegar a ver lo propio con ojos foráneos dada la presencia masiva de los franceses en el país: «Hasta ahora teníamos en España leyes francesas hechas por legisladores españoles, comedias francesas ejecutadas por cómicos españoles, modas francesas y modista ídem, pan español amasado por panaderos franceses, botas y sombreros franceses en pies y cabezas españolas, ropa usada en cuerpos españoles y refundida por ropavejeros franceses, yeguas y coches franceses conduciendo humanidades españolas y hasta dientes y muelas españolas mondadas con palillos franceses... y aquí ponga cada uno las etcéteras que guste que, por muchas que ponga, esté seguro que no sobrarán». LAFUENTE, Modesto. Teatro Social del Siglo XIX. Madrid: Establecimiento Tipográfico de D. F. de P. Mellado, 1846, p. 365. 
de lucro que percibe durante el viaje (los franceses trabajan por egoísmo; lo españoles por virtud: p. 252 ${ }^{15}$, la vanidad francesa expresada sin reparos («la Francia que va delante de todas las naciones en la industria y en las artes»: p. 258), la hipocresía del lenguaje (el empleo de «pardon, Monsieur» como salvaguardia para molestar, empujar o pisar a otra persona... que a su vez contesta con la misma fórmula) o el robo organizado de obras de arte, en referencia a los cuadros españoles del Louvre.

Estos ejemplos utilizan, sin mencionarla, otra tendencia habitual en la narrativa de viajes: la relación entre lo propio y lo nuevo, entre lo conocido y lo desconocido, normalmente para resaltar más sus diferencias que sus similitudes: no se viaja para ver lo mismo sino lo distinto; ponerlo de relieve es una forma de «demostrar» que se ha viajado. En los casos citados, se marca el énfasis en la novedad vista fuera, que remite in absentia a lo propio, pero en otros casos la variedad expositiva conlleva acentuar lo español, en general para aludir a una carencia o disfuncionamiento en contraste con el exterior, donde el problema no existe o es de menor gravedad. Por ejemplo, de España se resalta la inseguridad de los caminos, la incomodidad y fragilidad de los vehículos, el alojamiento, la pobreza evidente, el mal gobierno ${ }^{16}$, el drama repetido de la emigración y del exilio ${ }^{17}$ y el descuido de lo propio, tanto en el interior como en el exterior: la embajada en La Haya servida por una sola persona... que lleva un año sin cobrar sus haberes (p. 409). Con este último punto se puede relacionar el amargo comentario de Tirabeque al finalizar el viaje: «Ayer todas las tierras que hemos corrido eran nuestras y hoy somos en ellas tan extranjeros como los chinos: ayer éramos los amos y hoy no nos entienden el habla» (521).

Todo lo anterior nos lleva a decir que el viaje le permite a Lafuente realizar dos descubrimientos: el primero y fundamental es la existencia concreta de una Europa dinámica, organizada y moderna, cuyos logros, convenientemente adaptados, podrían revitalizar al país del autor. El se-

${ }^{15}$ Sobre la percepción hispana del comportamiento francés en el terreno económico durante aquel tiempo es útil la consulta de NUNLEY, Gayle R. Scripted geographies: travel writings by nineteenth-century. Spanish authors. Lewisburg: Bucknell University Press, 2007, pp. 58-59.

${ }^{16}$ Uno de los recursos de crítica más frecuentes es la ironía de contenido político (tema privilegiado en casi toda la obra de Lafuente): unos riachuelos vascos estarán «más torcidos que la marcha de nuestros gobiernos» (p. 18) y la villa de San Juan de Luz sufre unos golpes de mar parecidos a «los furiosos embates que de todos lados del Congreso está sufriendo actualmente el ministerio González, que no sé si tendrá fuerza para resistir y rechazar las embravecidas olas del salón de Oriente» (p. 25).

${ }^{17}$ Francia acoge diferentes oleadas de españoles, sobre todo durante la primera mitad del siglo XIX: afrancesados, liberales, absolutistas, carlistas, cristinos. No extraña que en nuestra obra los viajeros se entrevisten con Manuel Godoy y visiten la tumba de Leandro F. de Moratín en el cementerio del Père Lachaise (p. 192). De gran interés y centrado en estos años es el estudio de LEBLAY, Anne. L'Émigration espagnole à París (1813-1844). París: Ecole nationale des chartes, 2004. 
gundo es una forma personal de convertir la experiencia viática en relato de viaje, construyendo su texto con una gama de rasgos que van a dar una personalidad cierta a esta serie literaria en su versión contemporánea. Estos dos motivos bastan para considerar Viajes como un texto de referencia en la historia de la literatura viática española.

\section{LA PERSPeCtiva de Mesonero Romanos}

Después de un primer viaje por Francia y Bélgica entre agosto de 1833 y mayo de 1834, Ramón Mesonero Romanos, realiza otro entre junio de 1840 e invierno de 1841, según recoge en Recuerdos de viaje por Francia y Bélgica en 1840-1841, publicado en 1862 (incorporando materiales del viaje anterior) y ampliado en 1881. Conviene recordar que Mesonero Romanos llegó a poseer una de las mejores bibliotecas privadas de Madrid y que entre sus libros ocupaban parte no desdeñable los de «Geografía y viajes» (127 títulos), en cantidad inferior respecto a los de «Literatura amena» (372) pero superior a los de «Historia y crítica literaria» (50) ${ }^{18}$. Además, en 1831 Mesonero había publicado Manual de Madrid, libro que, por la riqueza de su información, se convirtió pronto en indispensable para conocer la ciudad ${ }^{19}$ : a partir de su propia experiencia como estudioso de Madrid, Mesonero disponía de sobrada competencia para observar y evaluar la entidad de las ciudades que habría de visitar. No olvidemos tampoco sus conocimientos de literatura extranjera, en particular de la francesa, valorada reiteradamente a través de la gran cantidad de autores y de textos que cita (y con los cuales parece tener cierta familiaridad), de los libros que posee y de los adquiridos durante sus viajes (alude en particular a la compra, nada más ponerse a la venta, de Le Retour de l'Empereur, serie de Víctor Hugo dedicada a Napoleón ${ }^{20}$ ), así como de sus lecturas históri-

${ }^{18}$ Los datos y la denominación de las diferentes categorías se deben a COLONGE, Chantal. «La bibliothèque de Mesonero Romanos». En: VV.AA. Recherches sur le monde hispanique au dix-neuvième siècle. Lille: Editions Universitaires, 1973, pp.129-148 (los datos, en p. 147).

${ }^{19}$ Incluía datos que podríamos calificar de turísticos, como información específica para forasteros sobre monumentos civiles y religiosos, casas de huéspedes, paseos y jardines, diversiones públicas, «Un día en Madrid», etc. Su autor afirmaba: «Creo haber tenido presente cuanto se ha publicado acerca de Madrid». MESONERO ROMANOS, Ramón. Manual de Madrid. Descripción de la corte y de la villa. Madrid: Imprenta de D. M. de Burgos, 1831, p. IV.

${ }^{20}$ Serie «en la cual hay trozos dignos por sí solos de inmortalizar a aquel ilustre vate» y de la que cita un breve fragmento. MESONERO ROMANOS, Ramón. Recuerdos de viaje. Madrid: Miraguano, 1983, p. 207. Todas nuestras citas provienen de esta edición, que retoma la de La Ilustración Española y Americana (Madrid, 1881), la cual suponía una ampliación y corrección de la de 1862 (esta a su vez corregía y aumentaba la primera, de 1841, editada en Madrid en la Imprenta de D. M. de Burgos). 
cas, sin dejar de lado incluso las guías urbanas. No extraña, pues, que Mesonero conozca los escritos extranjeros sobre España, en particular los franceses. Y el balance de sus lecturas resulta más bien negativo: de sus numerosas referencias sólo rescata una, Itinéraire de l'Espagne et du Portugal, de Germond de Lavigne (París, 1860), «sin disputa el mejor o, más bien, el único de los extranjeros que han consignado una descripción completa y acabada de nuestro país en su estado actual» (p. 35). Cabe observar que las exigencias del escritor madrileño no son pocas: un estudio completo de España centrado en la realidad presente. En este caso ello es posible, de Lavigne conoce España y es un excelente traductor de clásicos hispanos al francés (desde Fernando de Rojas a Pérez Galdós), aunque se le atribuya, con motivo o sin él, la sugerente frase de que «no se puede viajar a España sin antes hacer testamento».

El Curioso Parlante dibuja con burla y enojo al literato extranjero-tipo (en particular al francés) en su singular tarea de escribir sobre lo que ignora: apenas atraviesa las provincias vascongadas, ya está trazando cuadros «originales» traducidos de Walter Scott. Relata luego pretendidos lances con damas españolas de sangre caliente, incluyendo, para más picante, los celos colaterales del novio. Llegando a Burgos cuenta la historia del Cid acaecida poco después de la conquista de Granada... Critica, bastante molesto, que no entiendan francés en las posadas de Castilla. Lamenta no haber encontrado ladrones por el camino (por aquello del colorido local) y terminará contando sabrosas anécdotas como la del bandolero andaluz que, enamorado de la princesa Guiomar, acabó de Virrey del Perú, donde reside actualmente.

No han de faltar las corridas de toros en la Puerta del Sol con muerte de catorce hombres y cincuenta caballos, la olla podrida, la tertulia, el fandango, las señoras de navaja en liga, la siesta bajo palmas y limoneros, etc.: todo es bueno como materia de unas pretendidas Impresiones de via$j e$, mejor en varios tomos. Y Mesonero ofrece una amplia lista de autores y títulos que ilustran su irritación: entre ellos, Borrow, Gautier y, sobre todo, el inevitable Alejandro Dumas (De París à Cadix) ${ }^{21}$, a quien se opone en su visión de una España de pandereta y la de otros lugares visitados, por ejemplo en sus críticas sobre la ciudad de Lieja (comidas, hote-

${ }^{21}$ La lista citada es: Charles Didier (Six mois en Espagne), Roger de Beauvoir (La Porte $d u$ Soleil), Théophile Gautier (Tras-os-montes), Alexandre Dumas (De Paris à Cadix), Challamel (Un été en Espagne), Georges Borrow (La Bible en Espagne), Giraud y Desbarolles (Deux artistes en Espagne) «y otros muchos que sería enojoso recordar» (p. 281). En lo que concierne a Six mois en Espagne, no hemos visto tal obra referida a ese autor: quizás se trate de Une année en Espagne, publicada en 1837 en París por la Librairie de Dumont. En cambio, Six mois en Espagne puede deberse a Giuseppe Pecchio, traducida al francés y publicada en 1822 en París por Alexandre Corréard Libraire. En su primera edición, la grafía del título del libro de Gautier es Tra los montes (1843). 
les, etc., pp. 258-259). En fin, la ligereza del viajero francés culmina en el diario de uno de ellos pasando en barco cerca del archipiélago canario: «Sábado 24, pasamos cinco leguas al Norte de Canarias, cuyos habitantes me han parecido en extremo amables y hospitalarios» ${ }^{22}$.

Mesonero Romanos reacciona frente a una determinada lectura del Otro (en particular la francesa de la época) y propone la suya, basada en los puntos siguientes: un amplio bagaje cultural incorporado (sus propias lecturas sobre los lugares a visitar), la concentración del relato en torno a lo verdaderamente visto, la relegación de lo personal a un segundo plano, el tratamiento del asunto con arreglo a la experiencia vivida ${ }^{23}$ y narrar con brevedad, sin inflar artificialmente con anecdotarios o historias remotas de los pueblos visitados (pp. 10 y $129^{24}$ ). Tal es el método de lectura y de escritura que el autor nos propone. El resto del libro va a ser la puesta en práctica, con mayor o menor rigor, de este método: también Mesonero se apoya en la anécdota o en el recurso historicista más o menos justificado.

Para abreviar nuestra exposición, nos limitaremos aquí al espacio que nuestro visitante privilegia con mayor fruición y detenimiento: la capital de Francia ${ }^{25}$. Lo primero a destacar es que París, ya antes de ir, forma parte de lo que podemos llamar la «biblioteca mental» del viajero:

Todos los monumentos que le salen al paso, todos los sitios que pisa, le son ya conocidos de antemano por los cuadros del artista o por las relaciones del viajero; y sin necesidad de preguntar a nadie, adivina y reconoce que aquellos arcos

${ }^{22}$ Recuerdos de viaje, op. cit., p. 28. Anotemos que el Semanario Pintoresco Español (1836-1857), dirigido por Mesonero Romanos, critica el comportamiento de tales extranjeros y también el de los españoles que salen al exterior y no ponen por escrito su visión del otro, algo que el semanario considera como una acción formadora e incluso patriótica: AYMES, Jean-René. Voir, comparer, comprendre. Regards sur l'Espagne des XVIIIe et XIXe siècles. París: Presses de la Sorbonne Nouvelle, 2004, pp. 287-288. También hemos visto una actitud muy parecida en la obra aquí comentada de Modesto Lafuente. Una amplia panorámica de la imagen de España en los viajeros franceses se puede encontrar en: BENNASSAR, Bartolomé y Lucile. Le voyage en Espagne. Anthologie des voyageurs français et francophones du XVIe au XIXe siècle. París: Robert Laffont, 1998.

${ }^{23} \ll[\ldots]$ que ninguna princesa ni cosa tal nos salió al camino; que ningún entuerto ni desaguisado se cometió con nosotros; que tampoco fuimos objeto de un especial agasajo; y que, en fin, entramos en la región gálica como Pedro por su casa, lo mismo que ellos (los galos) entran cada y cuando les place por nuestra España (p. 21).

24 «[...] y huyamos también del extremo de los viajeros franceses, que a propósito de impresiones de viaje nos reimprimen toda la historia de los pueblos que visitan, a contar de los tiempos fabulosos, y todas las relaciones más o menos críticas que encuentran al paso» (p. 129).

${ }^{25}$ En torno al atractivo de París sobre los escritores españoles de aquellos años es aconsejable la consulta de: AYMES, Jean-René. Españoles en París en la época romántica 1808-1848. Madrid: Alianza, 2008, especialmente pp. 27-181. Como testimonio de la época, pocos superan el de OCHOA, Eugenio de. París, Londres y Madrid. París: DramardBaudry et Cie., Successeurs, 1861, pp. 1-237. 
monumentales que mira a su derecha son los del acueducto de Arcueill; que aquellos palacios y bosques que tiene a su izquierda son los de Meudum y de SaintCloud que aquel severo edificio que descubre en el fondo es el Hospicio y castillo de Bicêtre, que aquella inmensa cúpula que se destaca en la altura [...] (p. 77).

Como ya hemos visto en Modesto Lafuente, el recorrido de Mesonero por el célebre cementerio del Père Lachaise es uno de los momentos más emotivos de su estancia parisina. Allí va a rendir culto a La Fontaine, Molière, Beaumarchais, Jacques Delille, Benjamin Constant y otras personalidades familiares para el escritor, sin olvidar a algunos españoles como Leandro Fernández de Moratín, cuyos retratos presiden su gabinete de trabajo. Y algo parecido se podría decir, en el plano pictórico, sobre su paseo por el Louvre y su reencuentro allí con la escuela española (pp. 143-144).

En resumen, Mesonero Romanos viene a ser un ejemplo perfecto de los viajeros leídos que intentan verificar las correspondencias y divergencias entre lo que han percibido en los libros y la realidad que contemplan durante el viaje. Y debemos reconocer que el Curioso Parlante siente a veces la tentación de adaptar lo que ahora ve a lo que antes ha leído: "Cuando uno llega a París, se figura que todos cuantos tropieza son hombres grandes [...]; así que no había calvo que luego no tomase [yo] por Béranger, ni rostro alegre que no calificase de Jouy, ni lánguido a quien no llamase Lamartine, ni facciones abultadas y espaciosa frente que no fueran las de Víctor Hugo, ni mirar penetrante que no me denunciase a Scribe» (p. 77). No obstante, según sugiere el mismo tono de la cita, nuestro autor guarda cierto equilibrio, no adapta ciegamente lo visto a lo leído sino que enriquece su biblioteca mental con la percepción directa y distendida de la realidad. Ello se aprecia muy bien en la actividad que Mesonero parece saborear más intensamente: realizar su propia «lectura» mediante el libre callejeo por la capital ${ }^{26}$. Y a continuación dedica diez páginas (en la edición con-

${ }^{26}$ Junto con Modesto Lafuente, como hemos visto, Mesonero Romanos sugiere una de las primeras definiciones españolas a esta actividad: «Hay en el idioma francés un verbo y un nombre que se aplican especialmente a la vida parisiense, y son el verbo flâner y el adjetivo flâneur. No sé cómo traducir estas voces, porque no hallo equivalente en nuestra lengua ni significado propio en nuestras costumbres, pero usando de rodeos diré que en francés quiere decir: «andar curioseando de calle en calle y de tienda en tienda» y ya se ve que el que tratara de flanear largo rato por la calle Mayor o la de la Montera, muy luego daría por satisfecha su curiosidad [porque no hay mucho que ver]» (p. 109).

Se puede considerar que el término (y acaso su referente práctico) está entrando en nuestra lengua por esos años. El argentino Sarmiento se hace eco de esa novedad en un texto suyo de 1846 (véase como ambos autores vinculan el concepto a la capital francesa): «El español no tiene una palabra para indicar aquel farniente de los italianos, el flâner de los franceses [...]. El flâneur persigue también una cosa que él mismo no sabe lo que es; busca, mira, examina, pasa adelante, va dulcemente, hace rodeos, marcha y llega al fin..., a veces a orillas del Sena, al boulevard otras, al Palais Royal con más frecuencia. Flanear es un arte que sólo los Parísienses poseen en todos sus detalles». SARMIENTO, Domingo Faustino. Viajes por Europa, Africa i América. Madrid: CSIC, 1993, p. 99. 
sultada) a la que parece ser la actividad más atractiva de las que un español puede realizar en París: admirar joyerías, ópticas, peluquerías, sastrerías y todo tipo de comercios con artículos primorosamente expuestos, capaces de satisfacer el consumismo más exigente del forastero recién llegado a la capital francesa.

Por otra parte, Mesonero Romanos no duda en oponer las lecturas de otros autores a su experiencia propia de los lugares visitados: a lo antes dicho sobre Dumas y Lieja podemos añadir sus críticas ante quienes defienden el pretendido tono o carácter español de los pueblos de Flandes y sobre todo de la ciudad de Brujas, «remedo de las ciudades españolas» (p. 246): la dominación hispana no resultó allí ni grata ni duradera; las tropas de Juan de Austria, de Alba o de Espínola no iban a construir sino a dominar Flandes por la fuerza de las armas. Además, todo el que pasee por las calles de dicha ciudad belga verá un tipo físico propio del lugar (mejillas sonrosadas, tez transparente, ojos azules, labios bermejos, pelo rubio y ensortijado): exactamente el de los personajes que David Teniers situó como protagonistas de sus lienzos. Podemos observar que el cuadro, especie de libro gráfico, es tomado aquí como referencia: un individuo es de tipo indígena si corresponde al representado en la pintura; esta se convierte así en un peculiar sistema de lectura de la realidad. Y notemos de paso que Mesonero parece prestar más credibilidad a la pintura que a lo leído en algunos relatos de impresiones viajeras.

Hay también ocasiones en que el libro desempeña un papel fundamental: ciertos lugares o edificios han cambiado tanto con los años que es difícil percibir en ellos lo que fueron en otros tiempos (todos hemos visitado castillos, iglesias o poblaciones que apenas dejan intuir su grandeza pasada). Así sucede cuando Mesonero se refiere a diversos lugares de los Países Bajos: puede que un espacio concreto ya apenas diga nada de su historia y que la única justificación de su interés se encuentre en las páginas del libro. Aquí es la biblioteca material (la propia del viajero o la consultada para la ocasión) la que de algún modo anima ese espacio reactualizando para el lector lo que allí realizaron sus protagonistas. Pero aparte de esos momentos, Mesonero Romanos se afirma en el relato como un visitante con una consistente biblioteca mental que no duda en oponer a su experiencia concreta renovándola en cada momento: no se pliega a juicios externos sino que los pone a prueba mediante una metodología que le es propia y a la que él jamás está dispuesto a renunciar. Es así como el viaje le hace discreto según escribiera Cervantes, en el sentido de ser capaz de discernir y de afirmarse como sujeto de su propio periplo. 


\section{El ITINERARIO DE ÁNGEL FERNÁNDEZ DE LOS RÍOS}

Como los escritores precedentes, Fernández de los Ríos expresa una clara indignación frente a la imagen de España transmitida por autores extranjeros, particularmente los franceses, y considera llegada la hora de que los españoles no sólo presenten su propia versión de la tierra hispana sino también de la gala pero, al igual que Mesonero Romanos, evitando exageraciones y falsedades:

[...] apelo a las relaciones de viaje con que se han hecho sudar estos últimos años las prensas de París y señaladamente a las guías del viajero en España escritas para uso de los franceses en su idioma. Hacíase sentir la necesidad de que siguiendo su ejemplo, nos entrometiéramos nosotros también en territorio francés [...] y oponiendo a su sistema de inventar y escribir sin consideración, el de pintar con exactitud e imparcialidad lo bueno y lo malo que encontramos al paso, dejando aparte el amor patrio exagerado y provistos de bastante calma para juzgar desapasionadamente ${ }^{27}$.

Además, el libro, en la parte que media entre Madrid y la frontera, ha de servir también para informar verazmente a los visitantes extranjeros. Así, Fernández de los Ríos admite como cierta la negativa imagen de las paradas españolas de diligencia, asaltadas por incómodos mendigos, lo mismo que la carestía y mala calidad de las fondas castellanas, mientras que las vascas pueden parangonarse en comodidad y aseo con las de Francia (p. 12). En cambio, las catedrales francesas (de las que sólo valen las fachadas) no resisten la comparación con la suntuosidad de las españolas, lo cual no impide el cuidado ejemplar de los galos en promocionar sus monumentos, cuidado que debería inspirar a los españoles (pp. 33 y 36). Tampoco es de su agrado que en Francia las diligencias no esperen a los viajeros, que estos coman con singular voracidad o que, dado lo barato del precio, viaje en coche todo el mundo (grisetas, artesanos, militares, aldeanas, con sus incómodos bultos, etc.), mientras que en España lo hace esencialmente la «clase acomodada» (pp. 20-21). En resumen, estos ejemplos nos muestran lo que será la tónica general del libro: a pesar de las precauciones ya indicadas y de la sucesión de datos numerosos y con frecuencia muy precisos, no van a faltar las valoraciones claramente subjetivas, diseminadas entre las informaciones. Tanto es así que concentraremos nuestra exposición en torno a las dos vertientes que parecen caracterizar este texto: la que podríamos vincular más bien con el manual de viajeros o guía turística y la que correspondería más rigurosamente al relato viático, aun teniendo en cuenta la existencia de numerosos puntos comunes entre ambos discursos.

${ }^{27}$ FERNÁNDEZ DE LOS RÍOS, Ángel. Itinerario descriptivo, pintoresco y monumental de Madrid a París. Madrid: D. Ignacio Boix, 1845, p. 2. 


\section{Entre la guía viajera...}

Itinerario ofrece una acumulación de datos que, por su volumen y por su presencia sistemática, superan con creces lo habitual en el relato de viaje. Baste citar la siguiente lista, no exhaustiva: situación geográfica de la ciudad, habitantes, origen y evolución, edificios notables (por arte, historia, religión, administración, domicilio de personas ilustres), murallas, bancos, casas de beneficencia, bibliotecas, teatros, baños, hoteles, restaurantes, ríos, plazas, paseos, fuentes, coches de alquiler y otros medios de transporte urbano, mercado, industria local, economía, partido judicial, comunicaciones con el exterior, hijos ilustres, cantidad de habitantes (en algún caso, como en Miranda de Ebro, incluso de contribuyentes), tipo de autoridades, etc. A la información sobre los lugares visitados se suma la referente a las etapas del trayecto: habitantes de todas las ciudades y pueblos atravesados, distancias entre ellos, tipos de coches, funcionamiento de las postas, sin olvidar multitud de datos cuantitativos como la producción agrícola de algunas regiones, el presupuesto del gobierno francés para construcciones ferroviarias (cuando en España todavía no existe el camino de hierro), las cifras de muertos en los trenes ingleses, etc. El texto incluye también una gran cantidad de ilustraciones (en general dos o tres por página), cuya función, según se explicita al comienzo, es reforzar el contenido documental del libro ${ }^{28}$. Finalmente, Itinerario se abre y se cierra con gráficos que presentan la lista de lugares del recorrido con sus distancias respectivas, las compañías y horarios de transporte terrestre y marítimo, y la descripción pormenorizada de itinerarios de Madrid a la mayor parte de las grandes ciudades europeas (Londres, Estocolmo, San Petersburgo, Viena, Constantinopla, etc.).

Observemos que esas informaciones se dirigen esencialmente al futuro viandante y le conciernen en la medida en que vaya a desplazarse; es decir, la escritura parece tener aquí una función sobre todo instrumental y su pertinencia se comprobará durante la realización del trayecto por parte del lector: será su propia experiencia viática la que otorgue valor a lo leído. En tal punto estamos más bien lejos del relato de viaje, dado que en este el viajero es/ha sido el propio autor y su texto tiene como función primordial volver sobre su propia experiencia y compartirla con el lector pero no necesariamente provocar el viaje. Su realización es una eventualidad subsidiaria, que tal vez surja o se extinga durante la lectura: la expe-

\footnotetext{
${ }^{28}$ Lo cual no impide que se hayan detectado algunas «inexactitudes», como las de utilizar tres vistas del castillo de Cornatel, aparecidas antes en El lago de Carucedo (1840), de Gil y Carrasco, para presentarlas como pertenecientes a castillos franceses. PICOCHE, JeanLouis. Un romantique espagnol Enrique Gil y Carrasco (1815-1846). Lille: Université de Lille III, 1972, tomo I, p. 636.
} 
riencia viática puede haber sido tan extrema que el lector admire el relato precisamente por la dificultad o por la imposibilidad de hacer un recorrido semejante.

En consonancia con lo anterior, el autor aspira a que los datos aportados tengan validez general, que sean realmente utilizables por cuantos viajeros hagan el recorrido Madrid-París. Por ello, en lugar de narrar lo que pasó quizás una vez (cuando el autor realizó su trayecto), más bien procura describir aquellos objetos, lugares, acciones, costumbres, etc., que tienen cierta estabilidad o continuidad temporal y que, por consiguiente, cualquier lector los pueda observar cuando se desplace. Algunas marcas formales así lo atestiguan como el recurso frecuente al presente habitual y a la indeterminación de la tercera persona («se deja», «éntrase en», «se llega», «pásase por», «se atraviesa»): la experiencia, individual en el relato viático, es aquí colectiva y, si en aquel es singulativa y pasada, aquí está garantizada como repetible.

Sin embargo, esa validez es más presupuesta que real. Por un lado, su perennidad es limitada: los datos no pueden superar la contradicción entre precisión y continuidad; cuanto más precisos son, más fácil es que se vuelvan rápidamente caducos, como el precio de los trenes en Francia o del alquiler de coches en Burdeos. Curiosamente, el relato de viaje convierte una experiencia única en perdurable por el acto de lectura, mientras que la guía de viajeros, confrontada con la realidad extratextual, puede perder fácilmente su vigencia: la forma de desplazarse descrita en Itinerario será muy pronto superada por la generalización del tren en casi toda Europa. Por otra parte, según ejemplifica muy bien esta obra, la guía contiene una segunda restricción, su carácter marcadamente directivo: selecciona lo que «se debe» visitar (una catedral y, en su interior, ciertas capillas, imágenes o cuadros) e incluso llega a disuadirnos de ver otros objetos, aspecto en el cual nuestro texto es particularmente reiterativo: «Varias otras iglesias hay en Burdeos, pero sin que en ellas pueda citarse cosa alguna de interés [...]. No merecen citarse las demás iglesias de Orleáns porque nada tienen de notable» (pp. 24 y 33) ${ }^{29}$. Semejante recurrencia puede sugerir que el escritor busca imponernos sus preferencias personales; sin embargo, tenemos la seria impresión de que la mayoría de sus opciones siguen como criterio lo que se puede llamar el (buen) gusto general, lo presupuesto como digno de interés para viajeros relativamente cultos: es la imagen del potencial visitante la que predomina, no la experiencia subjetiva del redactor del texto. En otros términos, el discurso textual no interesa tanto por su estructura, nivel estético o complejidad formal sino más bien como medio para dirigir la visita hacia un lugar u otro. Por ello construye una jerarquía determinada de objetos (lo imprescindible, lo digno de interés, lo

\footnotetext{
${ }^{29}$ Ver páginas 14 y 32, cada una con varios ejemplos.
} 
curioso, lo desdeñable). Y dado que lo importante es la validez de la información para el futuro visitante, no es necesaria la experiencia del propio viaje: habiendo efectuado en tren la etapa entre Orleáns y París, el autor del relato confiesa no haber visto nada por la velocidad del ferrocarril y nos informa de los lugares atravesados recurriendo a documentos leídos por él ${ }^{30}$. Incluso puede ir más allá: estando en Burgos, afirma no tener tiempo para visitar todo lo que la ciudad guarda de interés y remite al lector a ciertos libros que versan sobre la ciudad castellana ${ }^{31}$.

Por lo tanto, tenemos aquí un tratamiento de la figura del viajero que lo distingue del relato de viaje factual: en este hay un narrador-viajero que ha realizado el periplo y, con mayor o menor fidelidad, cuenta sus vivencias. En la guía, el «auténtico» protagonista es una proyección futura, el potencial visitante que ha de desplazarse por los lugares descritos: es, pues, una figura imaginaria, lo cual llama la atención en un discurso en principio caracterizado por la observación de lo real. Tenemos también el otro viajero, el autor del texto, que sí parece bien anclado en la realidad, pero recordemos que no siempre ha visitado todo lo que nos presenta: una guía de viaje puede confeccionarse sin desplazarse su autor a (todos) los lugares descritos en ella, según se muestra en Itinerario. Puesto que cabe la sospecha de que ello no sólo ha sucedido cuando el autor nos lo confiesa (recuérdense las ilustraciones de castillos «franceses» antes citadas), también cabe suponer cierta ficcionalización en la figura del viajero-relator que dice acompañar al visitante a lo largo del recorrido. En definitiva, podemos hablar de dos viajeros marcados ambos por la ficcionalidad (uno, el que ha de viajar, imaginado y otro, el que ha debido de viajar, al menos parcialmente imaginario); todo ello, insistimos, en un texto de tan marcada pretensión documental como el que ahora nos ocupa.

No olvidemos tampoco que el viajero imaginado, al cual se destina el texto, no descubre nada (puede que tampoco lo haya hecho el autor de la guía, en la medida en que no ha viajado y que se ha inspirado en otras guías), puesto que se ha de limitar a visitar lo que se le indica, evitando

\footnotetext{
${ }^{30}$ «[...] confesamos que habiendo pasado siempre esta travesía por el ferrocarril, no nos ha sido posible formar juicio alguno de ella; pero como esto no es cuenta para el visitante, tendremos necesidad de apelar a otros medios que muchas veces nos han sacado en el curso de nuestro itinerario de los apuros consiguientes [...] comenzamos la descripción llenando los huecos que resultan en nuestros apuntes con varios otros escogidos entre aquellos que nos parezcan más exactos» (p. 35).

${ }^{31}$ Se trata de Viaje (tomo 12) de A. Ponz, del Manual del viajero de R. Monge y de los Apuntes históricos sobre la Cartuja de Miraflores, de J. Arias de Miranda (p. 9). Itinerario está salpicado de referencias bibliográficas destinadas a profundizar en la información dada en el texto, a reemplazarla cuando sólo se la menciona o a apoyarla documentalmente. Ver más ejemplos en pp. 1, 3, 7, 9, 13 (parte española), 19, 21-23, 27 y 32-33 (parte francesa). Esas referencias, junto con los apéndices del comienzo y del final del libro además de sus numerosas ilustraciones, confirman la preocupación documental que preside a esta obra.
} 
desviarse o detenerse demasiado: el mismo término itinerario sugiere un camino marcado, que sigue los pasos de otros visitantes. En el relato de viaje la situación parece muy distinta; en primer lugar, sólo tenemos un viajero, el que ha hecho el recorrido total o parcialmente y una o varias veces: ya hemos visto que el lector puede -incluso suele- leer sin intención de desplazarse físicamente. En segundo lugar, el libro viático no somete su discurso a la servidumbre de la verificación como criterio de valor, sino que admite y valora la subjetividad del relato, como producto que es de una vivencia única e irrepetible por los demás (y con frecuencia por su propio protagonista). En tercer lugar, el viajero del relato sí parte en busca de lo desconocido, tanto para descubrir la realidad de la diferencia como para descubrirse a sí mismo durante el periplo, el cual suele tener un componente de prueba para quien lo realiza, por atenuado que este sea. Y en cuarto lugar, se comprende que la guía se base en la descripción: al contrario del relato de viaje, en ella no se trata de narrar una experiencia individual sino de presentar objetos de tal modo que provoquen en los visitantes una sensación parecida, estandardizada, en cadena (una impresión semejante en una multitud de consumidores: ¿no estamos ya en la lógica de la industria turística?).

\section{... y el relato de viaje}

En las líneas anteriores hemos enfocado Itinerario desde la perspectiva del manual de información o guía de viajeros y hemos mostrado que contiene numerosos ingredientes habituales de ella. Vamos a reflexionar ahora desde la perspectiva del relato de viaje refiriéndonos sólo a tres dimensiones discursivas, sin olvidar que ambos tipos de textos pueden compartir diferentes rasgos como las informaciones históricas, las referidas al transporte o el «catálogo» de los objetos que han de interesar al visitante, aunque sea bastante más extenso y sistemático en la guía de viajeros.

Tenemos, en primer lugar, la dimensión narrativa-predictiva: en Itinerario interviene un narrador que no sólo cuenta la historia pasada o circunstancias de sus visitas anteriores sino que también adelanta o aconseja una actividad determinada, unas veces de forma explícita: «Tolosa es la villa donde el viajero va a descansar por algunas horas» (p. 14) y otras simplemente sugerida: «Es muy digno de las visitas del forastero» (el cementerio de la Chartreuse en Burdeos: p. 24). Nótese que la actividad narratorial implica el control de la información que se ha de dar al lector, seleccionando lo que se trata y lo que se deja fuera del discurso. La restricción informativa puede incluso llegar a anunciarse de manera explícita: «Renunciamos a hablar de los deliciosos valles, de las frondosas colinas y los graciosos caseríos que se encuentran a un lado y otro del camino» (en la provincia de Álava: p. 12). 
Por otra parte, y según se percibe en esta última cita, la figura del narrador aparece personalizada en múltiples secuencias del texto: se presenta como un personaje central, que reflexiona, recuerda, opina, deja libre curso a sus sentimientos ${ }^{32}$, acompaña e informa al viajero, le aconseja y se pone en su lugar (imaginando su interés, sus preocupaciones o su cansancio) en una relación casi amistosa y todo ello queda establecido desde el principio del viaje: «Colocándonos a su lado comenzamos nuestra tarea de llamarle la atención hacia cada objeto que creamos digno de ella [...]. [El viajero es] nuestro compañero; [...] no sabemos de qué hablarle para

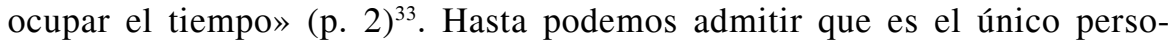
naje concreto del texto (considerado ahora como relato), puesto que el otro, el viajante, no aparece individualizado sino más bien como una entidad potencialmente múltiple, representante y resumen de los lectores viajeros: de hecho, a veces el texto parece dirigirse a dos tipos de viajero: al personaje «compañero» que va junto al narrador y al público que lee su relato y que acaso viaje posteriormente.

Finalmente, los dos puntos anteriores permiten poner de relieve el tercero, el componente ficcional del discurso, al que ya hemos aludido: tenemos un relato con su narrador, que es al mismo tiempo personaje de la historia; al final de la primera parte se dispone a descansar después de hablar «sin intermisión durante 80 leguas» (p. 16). Tenemos el o los otros personajes viajeros: el «compañero» con el que ahora se desplaza y el potencial viajante futuro. Tenemos también una casi continua prolepsis narrativa de las acciones por venir («encontrará», «tendrá ocasión de observar», «juzgará», «prepárese el viajero a ver», «le comunicaremos»). Y tenemos por fin un narrador capaz de proyectarse hacia el interior del personaje viajero: la contemplación de un determinado pueblo «no puede menos de disgustarle» (p. 4); admirando el castillo de Montesquieu en La Brède, le ha de venir naturalmente a la memoria la desgraciada suerte de sus vasallos (p. 22); ninguna población francesa de las dimensiones de Tours hará en él tan agradable impresión como esta ciudad (p. 29); y tampoco se olvide la cantidad de veces en que afirma de un determinado sitio que nada en él puede interesar al viajero ${ }^{34}$. Como es sabido, esa posibilidad de

${ }^{32}$ Desde la perspectiva actual puede resultar enternecedor su entusiasmado elogio al tren, que se ha de extender por el mundo como futuro cauce de paz entre los pueblos (p. 35).

${ }^{33}$ Esa personalización es todavía más notable en algún que otro «desliz» expresivo: como se ve en el ejemplo, nuestro personaje emplea regularmente el plural de modestia para referirse a sí mismo. En alguna ocasión, tal vez llevado por la intensidad del sentimiento, se le olvida y pasa a la primera persona del singular: «Tenemos por imposible [que el lector desconozca los nombres de ciertos pueblos vascos, célebres en la Guerra de la independencia], dudo mucho que haya nación que pueda presentar un formulario más completo y variado que la nuestra» (p. 11). Las cursivas son nuestras.

${ }^{34}$ Ver otros ejemplos en pp. 12, 19, 21, 24-25 y 32. 
situarse en el interior del otro tiene que ver con la omnisciencia propia del discurso ficcional, del que constituye uno de sus rasgos distintivos. Quizás aquí no sea mucho más que postulada (se puede argumentar que el narrador supone más bien que conoce), pero no deja de impregnar el texto haciendo que en muchos momentos bascule hacia el lado de la ficción.

Así pues, diríamos que Fernández de los Ríos desea presentarnos una guía de viajeros, con toda su artillería informativa, con un detallado recorrido de lugares y con un orden expositivo realmente minucioso pero sin renunciar a la dimensión viática, a sentirse viajero él mismo, como si no pudiera olvidar su propio periplo: se mete tan dentro de sus descripciones, datos y comentarios que llega a convertirse en personaje de su propio manual. Por momentos, esa combinación lo hace derivar de un lado a otro de las dos variantes pero el empeño en reunirlas debe ser destacado ${ }^{35}$.

\section{PARA CONCLUIR}

- Tomando a nuestros tres autores en su conjunto, se puede concluir que la diferencia más relevante de Fernández de los Ríos respecto a Lafuente y Mesonero Romanos quizás sea que los dos últimos están más claramente situados en la línea del relato de viaje que va a afirmarse posteriormente: en este la información documental emana de la vivencia viática y no es la condición previa para disfrutarla (lo cual resulta más propio de la guía de viajeros). Lafuente apuesta por la ficcionalización explícita, Fernández de los Ríos pretende combinarla con contenidos rigurosamente informativos y Mesonero se afirma como observador y crítico de las informaciones de los otros a partir de la experiencia propia y sin acudir a la dramatización de personajes y situaciones: son tres formas de entender el discurso viático en un momento capital de su historia.

- Al contrario de numerosos visitantes extranjeros del momento, nuestros autores no buscan el exotismo espacial o temporal sino la relación, desconocida u olvidada pero siempre instructiva, de los lugares visitados con España ${ }^{36}$ : los españoles tienen una historia en buena medida compartida con las tierras visitadas, por lo que han de restablecer el contacto con ellas para conocerse mejor a sí mismos ${ }^{37}$. Además, esos lugares, siendo más

${ }^{35}$ Una amplia selección de Itinerario ha sido incluida en: GOULEMOT, Jean M., LIDSKY, Paul y NASSAU, Didier. Le Voyage en France (1815-1914). París: Robert Laffont, 2010, pp. 396-445: posiblemente sea una adecuada forma de reconocimiento al mérito de la obra.

${ }^{36}$ La particularidad de nuestros autores destacaría aún más relacionándolos con las tendencias turísticas de la primera parte del siglo en Europa: BOYER, Marc. Histoire de l'invention du tourisme XVIe-XIXe siècles. La Tour d'Aigues: Éditions de l'Aube, 2000, pp. 79-249.

${ }^{37}$ Recuérdese esta confidencia de Fray Gerundio: «[...] apenas visité pueblo alguno de todos estos países en que no hallara recuerdos históricos españoles, más o menos gloriosos 
avanzados que la península, pueden inspirar el progreso de España si se sabe distinguir lo que presentan de positivo y de negativo.

- Por lo tanto, nuestros tres viajeros forman parte de los primeros escritores europeístas de la edad contemporánea en España: no viajan a Europa por obligación sino para buscar de algún modo el acercamiento a ella (mientras que tantos forasteros buscan en España justamente la distancia). Ni el viaje ni su destino es para ellos fortuito ni solamente personal: su interés supera al individuo y plasmarlo por escrito parece no ser sólo una satisfacción sino también una obligación de interés general.

- Se comprende, entonces, que estructuras discursivas como las de la guía de viajeros no basten para tal empresa y que Fernández de los Ríos intervenga como personaje, opine, cuestione, compare, aconseje y finalmente supere el marco del manual viajero. En efecto, la guía tiene un carácter esencialmente ambiguo puesto que, si por un lado es una llave de acceso a lugares y gentes, por otro viene a ser libro de libros en el sentido de que es resumen de muchas lecturas (además de una experiencia de viaje) y de que puede convertirse en el único texto de referencia, de confianza, para el viajero, el que le ha de permitir la culminación de su viaje con seguridad, confort y en breve tiempo. El descubrir, el cuestionar, el comparar, el saltarse itinerarios y límites temporales no forma parte de tal libro: el autor de Itinerario lo percibe así y nos ofrece una obra que describe, reflexiona y envía continuamente a otras.

- Y aunque no sea el objetivo de esta investigación, nótese que la intención de nuestros autores es, en parte, común a la de numerosos viajeros de las colonias o ex colonias americanas cuando recorren España a principios del siglo XIX, como el cubano Antonio Carlos Ferrer (Paseo por Europa y América en 1835 y 1836), a mediados de la misma centuria, como Domingo F. Sarmiento (Viajes por Europa, Africa i América) o incluso a principios del siglo XX, como los también argentinos Manuel Ugarte (Visiones de España) y Ernesto Mario Barreda (Las rosas del mantón), entre tantos otros visitantes citables. Si la Europa de los tres autores españoles es sentida como formando parte de la historia de España, para el viajero hispanoamericano España constituye un componente básico de su pasado y acaso también de su presente. A algunos tal realidad parece pesarles (Sarmiento) y a otros lo que les pesa sinceramente es la postración actual de la (antigua) metrópoli, que le impide ser una referencia a seguir para el Nuevo Continente, al contrario de lo que representa la Europa industrializada para España. La reacción «noventayochista» frente a la postración española no es, pues, nueva ni única, dado que se encuentra

para nuestra nación, pero todos interesantes para quien busca de buena fe el conocimiento de los sucesos que enlazan la historia del país propio con la de los extraños» (Viajes, op. cit., p. 263). 
en escritores españoles de la época romántica y también, cosa que a veces se olvida, entre los hispanoamericanos que visitan el país a lo largo del siglo XIX y comienzos del XX.

\section{REFERENCIAS BIBLIOGRÁFICAS}

ACHARD, Amédée. Un mois en Espagne (octobre de 1846). París: Ernest Bourdin, 1847. ARIAS DE MIRANDA, Juan. Apuntes históricos sobre la Cartuja de Miraflores de Burgos. Burgos: Imprenta de P. Polo, 1843.

AYMES, Jean-René. Voir, comparer, comprendre. Regards sur l'Espagne des XVIIIe et XIXe siècles. París: Presses de la Sorbonne Nouvelle, 2004.

—. Españoles en París en la época romántica 1808-1848. Madrid: Alianza, 2008.

BARREDA, Ernesto Mario. Las rosas del mantón (Andanzas y visiones por tierras de España). Buenos Aires: Sociedad Cooperativa Editorial Limitada, 1917.

BENNASSAR, Bartolomé y Lucile. Le voyage en Espagne. Anthologie des voyageurs français et francophones du XVIe au XIXe siècle. París: Robert Laffont, 1998.

BOYER, Marc. Histoire de l'invention du tourisme XVIe-XIXe siècles. La Tour d'Aigues: Éditions de l'Aube, 2000.

COLONGE, Chantal. «La bibliothèque de Mesonero Romanos». En: VV.AA. Recherches sur le monde hispanique au dix-neuvième siècle. Lille: Editions Universitaires, 1973, pp.129-148.

FERNÁNDEZ DE LOS RÍOS, Ángel. Itinerario descriptivo, pintoresco y monumental de Madrid a París. Madrid: D. Ignacio Boix, 1845.

FERRER, Antonio Carlos. Paseo por Europa y América en 1835 y 1836 por un joven habanero. Madrid: Imprenta de I. Sancha, 1838.

GOULEMOT, Jean M.; LIDSKY, Paul y NASSAU, Didier. Le Voyage en France (18151914). París: Robert Laffont, 2010.

LAFUENTE, Modesto. Teatro Social del Siglo XIX. Madrid: Establecimiento Tipográfico de D. F. de P. Mellado, 1846.

-. Viajes de Fray Gerundio por Francia, Bélgica. Holanda y orillas del Rhin. París: Librería de Garnier Hermanos, 1861.

LEBLAY, Anne. L'Émigration espagnole à París (1813-1844). París: Ecole nationale des chartes, 2004.

LEJEUNE, Philippe. Le Pacte autobiographique. París: Editions du Seuil, 1975.

—. Je est un autre. París: Editions du Seuil, 1980.

MELLADO, Francisco de Paula. Apéndice a la Guía del viajero en España. Madrid: Establecimiento Tipográfico, calle del Sordo, n. ${ }^{\circ} 11,1842$.

MESONERO ROMANOS, Ramón. Manual de Madrid. Descripción de la corte y de la villa. Madrid: Imprenta de D. M. de Burgos, 1831.

- Recuerdos de viaje. Madrid: Miraguano, 1983.

MONJE, Rafael. Manual del viajero en la catedral de Burgos. Burgos: Imprenta de Arnaiz, 1843.

NUNLEY, Gayle R. Scripted geographies: travel writings by nineteenth-century. Spanish authors. Lewisburg: Bucknell University Press, 2007.

OCHOA, Eugenio de. «El Español fuera de España». En: VV.AA. Los españoles pintados por sí mismos. Madrid: I. Boix Editor, 1844, tomo II, pp. 442-451.

—. París, Londres y Madrid. París: Dramard-Baudry et Cie., Successeurs, 1861.

PECCHIO, Giuseppe. Six mois en Espagne. París: Alexandre Corréard Libraire, 1822.

PICOCHE, Jean-Louis. Un romantique espagnol Enrique Gil y Carrasco (1815-1846). Lille: Université de Lille III, 1972, tomo I. 
PONZ, Antonio. Viaje de España. Madrid: Viuda de Ibarra, hijos y compañía, 1783, tomo XII.

QUETIN. Guide du voyageur en Espagne et en Portugal. París: Librairie de L. Maison, Editeur des Guides Richard, 1841.

SARMIENTO, Domingo Faustino. Viajes por Europa, Africa i América. Madrid: CSIC, 1993.

UGARTE, Manuel. Visiones de España (Apuntes de un viajero argentino). Valencia: Federico Sempere y Cía., Editores, 1904.

Fecha de recepción: 18 de marzo de 2010

Fecha de aceptación: 8 de septiembre de 2010 